\title{
PENGGUNAAN MEDIA KARTU DOMINO PECAHAN SENILAI DALAM PEMBELAJARAN MATEMATIKA BERBASIS PENDEKATAN STEM
}

\author{
Muhammad Fitrah \\ SMP Negeri 5 Sindue, Kab. Donggala, mfitrah_92@yahoo.com
}

\begin{abstract}
Abstrak. Penulisan artikel ini bertujuan untuk membahas penggunaan media kartu domino pecahan senilai dalam pembelajaran matematika divariasikan dengan pendekatan STEM. Penggunaan media ini diharapkan dapat menjadi salah satu alternatif dalam meningkatkan pemahaman konsep serta motivasi siswa dalam pembelajaran matematika khususnya materi pecahan senilai. STEM merupakan pendekatan pembelajaran yang mengintegrasikan empat bidang, yaitu sains, teknologi, engineering, dan matematika. Variasi penerapan pendekatan STEM dengan penggunaan media kartu domino bertujuan agar media pembelajaran ini dapat terus digunakan seiring dengan perkembangan zaman. Kedepannya saya akan membuat sebuah game domino digital/domino online yang berbentuk pecahan senilai.
\end{abstract}

Kata Kunci. Media Kartu Domino, Pecahan Senilai, Pendekatan STEM

Pendidikan 4.0 merupakan pendidikan yang bercirikan pemanfaatan teknologi digital dalam proses pembelajaran yang mampu membuat proses pembelajaran berlangsung tanpa batas ruang dan waktu. Untuk mengimplementasikan hal tersebut, guru harus banyak melakukan inovasi dalam mendesain media pembelajaran. Salah satu media pembelajaran dalam pecahan senilai adalah menggunakan media kartu domino yang divariasikan dengan pendekatan STEM.

Berdasarkan hasil penelitian National STEM Education Center (2014), pendidikan STEM menghubungkan ke empat komponen yaitu sains, teknologi, enjiniring, dan matematika, untuk digunakan dalam kehidupan sehari-hari maupun bidang profesi yang digeluti.Pendidikan STEM memberi pendidik peluang untuk menunjukkan kepada peserta didik betapa konsep, prinsip, dan teknik dari sains, teknologi, rekayasa, dan matematika digunakan secara terintegrasi dalam pengembangan produk, proses, dan sistem yang digunakan dalam kehidupan sehari-hari mereka. Oleh karena itu, definisi pendidikan STEM diadopsi sebagai pendekatan interdisiplin pada pembelajaran (Reeve, 2013).

Tsupros (2009) menyatakan bahwa pendidikan STEM terpadu adalah pendekatan interdisiplin pada pembelajaran, yang di dalamnya peserta didik menggunakan sains, teknologi, teknik, dan matematika dalam konteks nyata yang mengkoneksikan antara sekolah, dunia kerja, dan dunia global, sehingga mengembangkan literasi STEM yang memampukan peserta didik bersaing dalam era ekonomi baru.

Penerapan STEM dapat didukung oleh berbagai metode pembelajaran. STEM yang bersifat integratif memungkinkan berbagai metode pembelajaran dapat digunakan untuk mendukung penerapannya (Ruiz-Gallardo, dkk, 2010).

Berdasarkan hasil observasi yang dilakukan di Kelas VII SMP Negeri 5 Sindue diperoleh data bahwa pemahaman konsep dan motivasi siswa dalam pembelajaran matematika masih sangat rendah khususnya pada materi pecahan senilai. Oleh karena itu, untuk mengatasi permasalahan tersebut, salah satu alternatif yang dapat kita lakukan adalah dengan penggunaan media kartu domino pecahan senilai yang divariasikan pendekatan 
STEM. Diharapkan dengan penggunaan media tersebut dapat meningkatkan pemahaman konsep serta motivasi siswa terhadap materi pecahan senilai.

\section{KAJIAN PUSTAKA}

\section{Media Kartu Domino Pecahan Senilai}

Media merupakan salah satu sarana yang digunakan pendidik untuk menyampaikan informasi kepada peserta didik. Media yang digunakan pendidik diharapkan dapat merangsang pikiran, perasaan, perhatian dan kemampuan atau keterampilan peserta didik sehingga dapat mendorong terjadinya proses belajar.

Kartu domino pecahan senilai adalah permainan dengan jumlah 28 kartu dimana setiap kartu terbagi dalam dua bidang dengan mata dadu yang berbentuk nilai suatu pecahan. Prosedur permainan kartu domino pecahan senilai sama saja seperti permainan domino pada umumnya. Setiap pemain menghubungkan kartu domino dengan nilai pecahan yang sama. Melalui permainan kartu domino ini diharapkan dapat memantapkan konsep pemahaman siswa terhadap materi pecahan senilai dan mengasah keterampilan menghitung siswa tanpa mencoret di atas kertas untuk menemukan pecahan senilai kartu domino tersebut.

Pecahan senilai adalah adalah pecahan-pecahan yang bernilai sama. Artinya, pecahan yang berbeda dapat bernilai sama asalkan perbandingannya tetap. Untuk menentukan pecahan senilai dapat dengan mengalikan atau membagi pembilang dan penyebutnya dengan bilangan yang sama.

Berikut disajikan Gambar 1. Media Kartu Domino Pecahan Senilai).

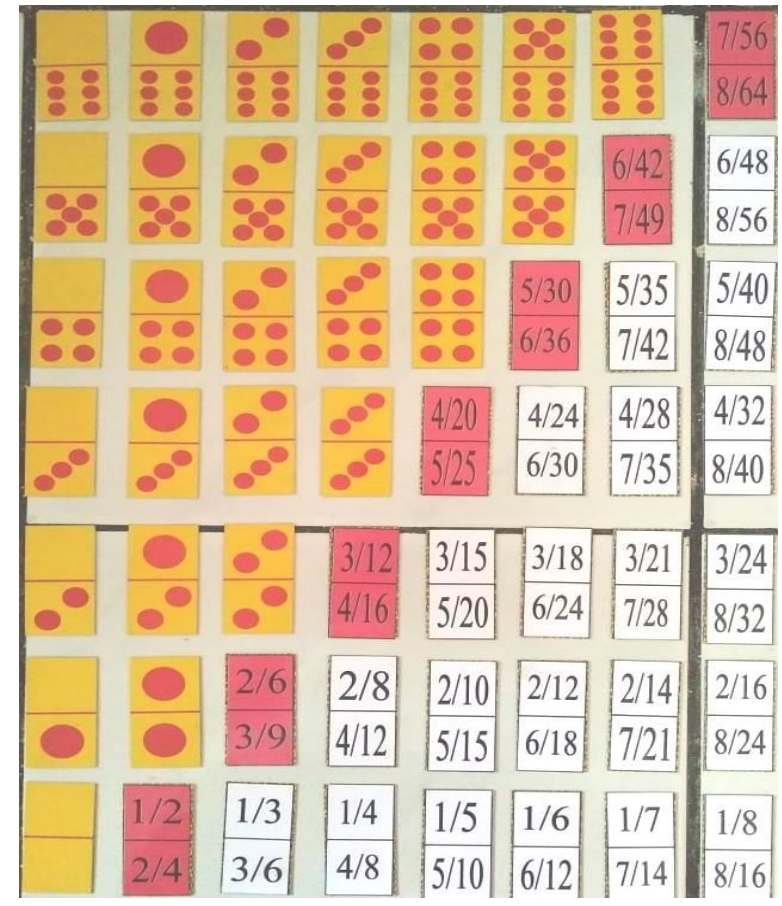

Gambar 1. Kartu Domino Pecahan Senilai 


\section{Pembelajaran Matematika}

\section{Belajar}

Belajar merupakan proses yang dilakukan seseorang untuk mendapatkan perubahan tingkah laku sebagai hasil interaksi dengan lingkungannya (Sugihartono, 2007: 74). Senada dengan pendapat tersebut, belajar menurut Sardiman (2011:21) adalah berubah. Dalam hal ini yang dimaksudkan belajar berarti usaha mengubah tingkah laku. Jadi belajar akan membawa suatu perubahan pada individu-individu yang belajar.

Menurut (Wina Sanjaya, 2009:107) belajar adalah proses berpikir. Belajar berpikir yaitu menekankan pada proses mencari dan menemukan pengetahuan melalui interaksi antar individu dengan lingkungannya.

\section{Matematika}

Istilah mathematics (Inggris), mathematic (Jerman) atau mathematick/wiskunde (Belanda) berasal dari perkataan lain mathematica, yang mulanya diambil dari perkataan Yunani, mathematike, yang berarti relating to learning. Perkataan itu mempunyai akar kata mathema yang berarti pengetahuan atau ilmu (knowledge, science). Perkataan mathematike berhubungan sangat erat dengan sebuah kata lainnya yang serupa, yaitu mathematein yang mengandung arti belajar (berpikir) (Erman Suherman, 2003:18). Matematika terbentuk sebagai hasil pemikiran manusia yang berhubungan dengan ide, proses, dan penalaran (Erman Suherman, 2003:16).

Sementara menurut Depdiknas (2006: 346) bahwa matematika meliputi aspek-aspek bilangan, aljabar, geometri dan pengukuran serta statistika dan peluang.

\section{Pembelajaran Matematika}

NCTM (National Coucil of Teachers of Mathematics) merekomendasikan 4 (empat) prinsip pembelajaran matematika, yaitu :

a. Matematika sebagai pemecahan masalah.

b. Matematika sebagai penalaran.

c. Matematika sebagai komunikasi, dan

d. Matematika sebagai hubungan

(Erman Suherman, 2003:298)

Matematika perlu diberikan kepada siswa untuk membekali mereka dengan kemampuan berpikir logis, analitis, sistematis, kritis, dan kreatif serta kemampuan bekerjasama. Standar Isi dan Standar Kompetensi Lulusan (Depdiknas, 2006:346) menyebutkan pemberian mata pelajaran matematika bertujuan agar peserta didik memiliki kemampuan sebagai berikut.

a. Memahami konsep matematika, menjelaskan keterkaitan antara konsep dan mengaplikasi konsep atau logaritma secara luwes, akurat, efisien dan tepat dalam pemecahan masalah.

b. Menggunakan penalaran pada pola dan sifat, melakukan manipulasi matematika dalam membuat generalisasi, menyusun bukti, atau menjelaskan gagasan dan pernyataan matematika.

c. Memecahkan masalah yang meliputi kemampuan memahami masalah, merancang model matematika, menyelesaikan model, dan menafsirkan solusi yang diperoleh. 
d. Mengkomunikasikan gagasan dengan simbol, tabel, diagram, atau media lain untuk menjelaskan keadaan/masalah.

e. Memiliki sifat menghargai kegunaan matematika dalam kehidupan, yaitu: memiliki rasa ingin tahu, perhatian, dan minat dalam pelajaran matematika serta sikap ulet dan percaya diri dalam pemecahan masalah.

Tujuan umum pertama pembelajaran matematika pada jenjang pendidikan dasar dan menengah adalah memberikan penekanan pada penataan latar dan pembentukan sikap siswa. Tujuan umum adalah memberikan penekanan pada keterampilan dalam penerapan matematika, baik dalam kehidupan sehari-hari maupun dalam membantu mempelajari ilmu pengetahuan lainnya.

\section{Pembelajaran Berbasis STEM}

Secara umum, penerapan STEM dalam perkuliahan/pembelajaran dapat mendorong peserta didik dapat mendorong peserta didik untuk mendesain, mengembangkan dan memanfaatkan teknologi, mengasah kognitif, manipulative dan afektif serta mengaplikasikan pengetahuan (Kapila, V. 2014).

Literasi sains dan teknologi merupakan hal yang tidak terpisahkan dari literasi matematika. Menghasilkan produk teknologi berdasarkan sains, umumnya selalu dijembatani oleh literasi matematika. Literasi matematika didefenisikan sebagai kapasitas seorang individu untuk mengidentifikasi dan memahami peranan yang dimainkan matematika terhadap dunia, untuk mengokohkan penilaian, dan mengikat matematika dengan cara yang sesuai dengan kebutuhan individu saat ini dan untuk kehidupan pada masa yang akan datang sebagai warga negara yang konstruktif, peduli dan reflektif (De Lange, J. 2000).

Dari uraian di atas penulis ingin membuat sebuah literasi digital dari penggunaan media kartu domino pecahan senilai. Adapun rancangan yang ingin saya buat yaitu membuat sebuah game domino digital/domino online yang dapat dimainkan secara digital. Bentuk dari domino digital tersebut adalah pecahan senilai seperti yang ada pada Gambar 1 di atas.

\section{PEMBAHASAN}

Fenomena yang terjadi di Kelas VII SMP Negeri 5 Sindue menunjukkan bahwa rendahnya pemahaman konsep dan motivasi siswa khususnya pada materi pecahan senilai, mendorong seorang guru untuk berinovasi mencari suatu alternatif media pembelajaran yang membuat siswa termotivasi untuk belajar matematika. Salah satu solusi yang kami terapkan untuk mengatasi permasalahan tersebut adalah penggunaan media kartu domino pecahan senilai yang divariasikan dengan pendekatan STEM.

Permainan kartu domino sudah tidak asing lagi bagi siswa di SMP Negeri 5 Sindue. Hal inilah yang membuat penulis memilih media tersebut dan juga karena media tersebut sangat mudah diperoleh dalam kehidupan sehari-hari. Penulis hanya memodifikasi kartu domino kertas dengan mengganti gambar pada sisi depan kartu domino yang tadinya berisi gambar bintik lingkaran (dot) dengan jumlah angka antara 0 (kosong) sampai dengan 6 yang terdapat dalam dua bidang menjadi gambar pecahan yang juga terbagi dalam dua bidang dengan nilai pecahan terendah $\frac{1}{8}$ dan nilai pecahan tertinggi $\frac{1}{2}$. Banyaknya kartu domino adalah 28 kartu dan terdapat 7 kartu domino yang mempunyai nilai pecahan 
sepasang (nilai perbandingan yang sama) namun berbeda penulisan angka pecahannya atau sering disebut dengan pecahan senilai.

Aturan permainan kartu domino pecahan senilai ini sama saja dengan permainan kartu domino pada umumnya, hanya saja disini siswa dituntut untuk lebih berpikir keras sebelum memasangkan kartu yang dimilikinya apakah nilai pecahannya sudah sama (senilai) dengan kartu domino terakhir yang diletakkan temannya sebelum gilirannya. Jadi, siswa dituntut untuk mandiri berhitung dalam menentukan pecahan senilai tanpa mencoret di atas kertas. Secara tidak langsung, media kartu domino pecahan senilai ini, selain meningkatkan pemahaman konsep dan motivasi siswa dalam pembelajaran matematika juga merangsang kemampuan kreatifitas serta keterampilan siswa dalam menyusun tata letak domino atau menerapkan strategi dalam bermain agar memperoleh kemenangan disetiap babak yang dimainkan. Hal ini sejalan dengan hasil penelitian Firman (2018) yang menggunakan media permainan kartu domino untuk meningkatkan keterampilan berhitung konversi pecahan desimal siswa kelas IV. Hasil yang diperoleh siswa terlatih dan antusias untuk menghubungkan tiap-tiap kartu domino dengan perasaan senang dan kompetitif. Siswa dengan semangat berhitung mengkonversi pecahan-desimal dan mereka teliti mengoreksi hasil jawaban dari temannya. Tidak hanya itu, siswa yang kemampuan hitungnya tinggi akan membantu siswa yang berkemampuan rendah dalam berhitung.

Merujuk pada narasi di atas maka penulis mencoba menggabungkan penggunaan media kartu domino pecahan senilai dengan pendekatan STEM. National Assessment and Educational Progress (NAEP) mengartikan Literasi Teknologi dan Rekayasa (TEL) sebagai kapasitas untuk menggunakan, memahami, dan mengevaluasi teknologi sebagaimana juga memahami prinsip dan strategi teknologi yang diperlukan untuk mengembangkan solusi dan mencapai tujuan (Firman et al., 2015). Dalam TEL, para peserta didik diharapkan mampu menerapkan cara-cara khusus untuk berpikir dan bernalar ketika melakukan pendekatan terhadap suatu masalah. NAEP merinci tiga area yang saling berhubungan dari TEL:

1) Technology and Society: teknologi melibatkan dampak terhadap masyarakat dan dunia alami, juga pertanyaan etis yang dimunculkan dari semua efek tersebut.

2) Design and Systems: mencakup hakikat teknologi, proses desain rekayasa yang mengembangkan teknologi, dan prinsip-prinsip dasar yang berkait dengan teknologi sehari-hari, termasuk memelihara dan mengatasi kesulitannya.

3) Information and Communication Technology: termasuk komputer dan perangkat lunak pembelajaran, sistem jejaring dan protokol, peralatan digital, dan teknologi lainnya untuk mengakses, mencipta, dan mengkomunikasikan informasi dan untuk memfasilitasi ekspresi kreatif.

Dari beberapa narasi di atas kedepannya saya akan membuat sebuah game domino digital/domino online yang dapat dimainkan oleh beberapa orang tanpa harus bertemu di sebuah tempat. Permainan domino tersebut dapat dimainkan dari belahan dunia manapun selama masih tersedia jaringan internet. Dalam prosesnya siswa menggunakan kemampuan sains (pengetahuan berhitung) dalam memahami konsep pecahan senilai. Selanjutnya siswa mendesain teknik (engineering) penyelesaian dalam memainkan kartu domino pecahan senilai dengan kemampuan matematika yang dimilikinya. Penggunaan media kartu domino digital nantinya diharapkan dapat menimbulkan motivasi siswa dalam pembelajaran matematika sehingga meningkatkan keterampilan proses berhitung dalam kehidupan seharihari.

Saya berharap kepada semua stake holder dalam dunia pendidikan agar dapat membantu untuk membuat game domino pecahan senilai secara digital/online. 
56 AKSIOMA, Volume 9 Nomor 1, Maret 2020

\section{PENUTUP}

Pesatnya kemajuan teknologi komunikasi dan informasi pada satu dekade mendatang menggugah hati penulis untuk menciptakan media pembelajaran matematika yang tidak lekang oleh perkembangan zaman.

\section{DAFTAR PUSTAKA}

De Lange, J. 2000. “The Tides They are A-Changing”. UMAP-Journal21(1): 15-36.

Depdiknas. 2006. Standar Isi dan Standar Kompetensi Lulusan untuk Satuan Pendidikan Menengah SMP-MTS-SMPLB.

Erman Suherman, dkk. 2003. Strategi Pembelajaran Matematika Kontemporer. Bandung: JICA.

Firman Tsabbit Abqari, dkk. 2018. Media Permainan Kartu Domino untuk Meningkatkan Keterampilan Berhitung Konversi Pecahan Desimal Siswa Kelas IV. Malang: http:journal.um.ac.id.

Kapila, V. \& Iskander, M. 2014. Lessons learned from conducting a K-12 project to revitalize achievement by using instrumentation in Science Education. Journal of STEM Education, 15 (1), pp. 46-51.

National STEM Education Center. 2014. STEM education network manual. Bangkok: The Institute for the Promotion of Teaching Science and Technology.

Reeve, E. M. 2013. Implementing science, technology, mathematics and Engineering (STEM) education in Thailand and in ASEAN. Bangkok: Institute for the Promotion of Teaching Science and Technology (IPST).

Ruiz-Gallardo, J.-R., Castano, S., Gomez-Alday, J. J. \& Valdes, A. 2010. Assesing student workload in problem based learning: Relationships among teaching method, student workload and achievement. Teaching and Teacher Education, 27, pp. 619-627.

Sardiman. 2011. Interaksi dan Motivasi Belajar Mengajar. Jakarta: Rajawali Pers.

Sugihartono, dkk. 2007. Psikologi Pendidikan. Yogyakarta: UNY PRESS.

Tsupros, N., R. Kohler, dan J. Hallinen. 2009. STEM education: A project To Identify The Missing Components. A collaborative study conducted by the IU1 Center for STEM Education and Carnegie Mellon University.

Wina Sanjaya. 2009. Strategi Pembelajaran Berorientasi Standar Proses Pendidikan. Jakarta: Kencana Prenada Media Group. 